\title{
Genomovars 11 to 18 of Pseudomonas stutzeri, identified among isolates from soil and marine sediment
}

Correspondence

Johannes Sikorski sikorski@research.haifa.ac.il

\author{
Johannes Sikorski, ${ }^{1}$ Jorge Lalucat ${ }^{2}$ and Wilfried Wackernagel ${ }^{1}$
}

\author{
${ }^{1}$ Genetik, Institut für Biologie und Umweltwissenschaften, Universität Oldenburg, Germany \\ ${ }^{2}$ Microbiologia, Departament de Biologia, Institut Mediterrani d'Estudis Avancats (CSICUIB), \\ Palma de Mallorca, Spain
}

The species Pseudomonas stutzeri is a non-fluorescent member of the genus Pseudomonas ( $\gamma$-Proteobacteria) displaying high genetic (Rius et al., 2001; Cladera et al., 2004) and physiological diversity (Rosselló et al., 1991). Strains of $P$. stutzeri have been isolated from a variety of environmental and clinical habitats (Sikorski et al., 2002a and references therein). Some strains received attention as model organisms because of their specific metabolic properties (Musarrat \& Hashsham, 2003; Obradors \& Aguilar, 1991; Rosselló-Mora et al., 1994; Zumft, 1997) and their ability for natural genetic transformation (Berndt et al., 2003; Meier \& Wackernagel, 2003; Sikorski et al., 1998, 2002b).

Published online ahead of print on 22 April 2005 as DOI 10.1099/ ijs.0.63535-0.

tPresent address: Institute of Evolution, University of Haifa, Mount Carmel, Haifa 31905, Israel.

Abbreviation: RAPD, random amplified polymorphic DNA.

The GenBank/EMBL/DDBJ accession numbers for the ITS1 rRNA gene sequences of genomovars 11 to 18 of Pseudomonas stutzeri are AY850023-AY850031.

Two phylogenetic trees based on 16S rRNA and ITS1 gene sequences and tables detailing DNA-DNA relatedness values and physiological properties of the genomovars are available as supplementary material in IJSEM Online.
Taxonomically, P. stutzeri strains have been grouped into 10 genomovars by DNA-DNA hybridization (García-Valdés et al., 2003; Rosselló et al., 1991; Rosselló-Mora et al., 1996; Sepúlveda-Torres et al., 2001; Ursing et al., 1995). In a recent population-genetic study, approximately 440 strains from soil and marine environments were studied by random amplified polymorphic DNA-PCR (RAPD-PCR) and the $16 \mathrm{~S}$ rRNA gene sequence was determined ( $>1450 \mathrm{bp}$ ) (Sikorski et al., 2002a) for 34 of the strains (several being representatives of the main RAPD groups). The 16S rRNA gene sequences suggested that seven representative strains (28a50, 28a39, 28a22 and 28a3, from soil close to Tel Aviv airport, Israel; 4C29, from marine sediment on the shore of the North Sea coast, Germany; 24a13 and 24a75, from a soil contaminated with mineral oil, Germany) and strain MT-1 (from Mariana Trench, Japan; Tamegai et al., 1997) were members of new genomovars. Based on their 16S rRNA gene sequence dissimilarity values, these eight strains were as different from each other and from reference strains of the established genomovars 1 to 10 as the genomovar reference strains differed from each other (Table 1). Moreover, the lowest dissimilarity value of any of these strains to each other or to a reference strain of an established genomovar $(0 \cdot 41 \%$; Table 1$)$ was larger than the maximum dissimilarity value observed among nine strains within three established genomovars $(0 \cdot 31 \%$; Table 1$)$. In the following, 
Table 1. 16S rRNA gene sequence dissimilarities

Strains: 1, Genomovar 1 reference strains CCUG 11256 ${ }^{\mathrm{T}}$, ATCC 17589, ATCC 17593; 2, genomovar 2 reference strains ATCC 17591, ATCC 14405, ATCC 17587; 3, genomovar 3 reference strains DSM 50227, AN10, AN11; 4, genomovar type strain CCUG $11256^{\mathrm{T}}$ (gv. 1) and reference strains ATCC 17591 (gv. 2), DSM 50227 (gv. 3), DSM 6084 (gv. 4), DSM 6082 (gv. 5), DSM 50238 (gv. 7), JM 300 (gv. 8), KC (gv. 9), CLN 100 (gv. 10).

\begin{tabular}{|c|c|c|c|c|}
\hline \multirow[t]{2}{*}{ Comparison } & \multicolumn{4}{|c|}{ Dissimilarity measures (\%) } \\
\hline & Mean & Median & Min. & Max. \\
\hline \multicolumn{5}{|l|}{ Within established genomovars } \\
\hline $1^{\star}$ & $0 \cdot 20$ & $0 \cdot 30$ & $0 \cdot 00$ & $0 \cdot 30$ \\
\hline $2^{*}$ & $0 \cdot 09$ & $0 \cdot 07$ & $0 \cdot 07$ & $0 \cdot 14$ \\
\hline $3^{*}$ & $0 \cdot 25$ & $0 \cdot 31$ & $0 \cdot 14$ & $0 \cdot 31$ \\
\hline \multicolumn{5}{|c|}{ Among established genomovars 1 to $10 \dagger$} \\
\hline 4 & $1 \cdot 34$ & $1 \cdot 38$ & $0 \cdot 07$ & $2 \cdot 23$ \\
\hline \multicolumn{5}{|c|}{$\begin{array}{l}\text { Comparison of reference strains of new genomovars } 11 \text { to } 18 \\
\text { to reference strains of established genomovars } 1 \text { to } 10^{\dagger}\end{array}$} \\
\hline Gv. $1128 \mathrm{a} 50$ & $0 \cdot 99$ & $0 \cdot 75$ & $0 \cdot 42$ & $2 \cdot 75$ \\
\hline Gv. $1228 a 39$ & $1 \cdot 31$ & $1 \cdot 19$ & $0 \cdot 63$ & $3 \cdot 11$ \\
\hline Gv. $1328 \mathrm{a} 22$ & $1 \cdot 23$ & $1 \cdot 01$ & $0 \cdot 69$ & $3 \cdot 06$ \\
\hline Gv. $1428 \mathrm{a} 3$ & $1 \cdot 07$ & $0 \cdot 83$ & $0 \cdot 42$ & $2 \cdot 86$ \\
\hline Gv. $154 \mathrm{C} 29$ & $1 \cdot 22$ & $1 \cdot 09$ & $0 \cdot 41$ & $3 \cdot 00$ \\
\hline Gv. $1624 a 13$ & $1 \cdot 25$ & $1 \cdot 22$ & $0 \cdot 69$ & $2 \cdot 58$ \\
\hline Gv. 17 24a75 & $2 \cdot 89$ & $2 \cdot 93$ & $2 \cdot 58$ & $3 \cdot 11$ \\
\hline Gv. 18 MT-1 & $1 \cdot 29$ & $1 \cdot 18$ & $0 \cdot 41$ & $2 \cdot 74$ \\
\hline Among new genomovars 11 to 18 & $1 \cdot 42$ & $1 \cdot 13$ & $0 \cdot 41$ & $3 \cdot 11$ \\
\hline
\end{tabular}

${ }^{\star}$ Affiliation of three members per genomovar was previously shown by DNA-DNA hybridizations (Rosselló et al., 1991).

†Genomovar 6 was reclassified as Pseudomonas balearica (Bennasar et al., 1996).

we present further data to support the identification of eight new genomovars including the results of DNA-DNA hybridization studies, sequence analyses of 16S-23S rRNA internally transcribed spacer regions (ITS1) and comparisons of physiological properties. Additionally, two strains (28a18 and 28a69) which were suggested by RAPD-PCR to belong to the new genomovars represented by strains 28a3 (genomovar 14) and 28a22 (genomovar 13), respectively (Sikorski et al., 2002a), were included in part of the studies.

Genomic DNA from the eight new genomovar reference strains and from strains $28 \mathrm{a} 18$ and $28 \mathrm{a} 69$ was isolated using the Genomic DNA kit from QIAGEN and from the reference strains of genomovars 1-10 by the method of Marmur (1961). DNA-DNA hybridizations were performed using a modification of the hydroxyapatite method as described by Ziemke et al. (1998). Reference DNAs were double-labelled with DIG-11-dUTP and biotin-16-dUTP, using a nicktranslation kit (Boehringer Mannheim). Sequences of the $16 \mathrm{~S}$ rRNA and ITS1 genes were determined as described by Guasp et al. (2000) and Sikorski et al. (2002a). Phylogenetic analysis was performed using the ARB package for $16 \mathrm{~S}$ rRNA gene sequences (Ludwig et al., 2004) and MEGA version 2.1
(Kumar et al., 2001) for ITS1 sequences. Physiological tests were done according to Smibert \& Krieg (1994).

The high DNA-DNA relatedness values of strain 28a18 with $28 \mathrm{a} 3(91 \%)$ and $28 \mathrm{a} 69$ with $28 \mathrm{a} 22(93 \%)$ indicate membership of the respective genomovar, as suggested by RAPDPCR (Sikorski et al., 2002a). In contrast, the DNA-DNA relatedness values of the eight representative strains of the new genomovars to each other and to the reference strains of the genomovars 1 to 10 were at or below the threshold value of $70 \%$ for species delineation (Table 2) except for two pairs (77\%, MT-1/28a22; 82\%, 28a3/24a13; Supplementary Table S1 available in IJSEM Online). However, the 16S rRNA and ITS1 gene sequence analyses group all of them into the same phylogenetic branch as the previously described strains of $P$. stutzeri (Supplementary Figs S1 and S2 available in IJSEM Online), indicating their phylogenetic affiliation with the P. stutzeri group. Additionally, physiological traits characteristic of the species $P$. stutzeri were present in the eight strains (see Supplementary Table S2 in IJSEM Online). Motility, denitrification and starch hydrolysis are characteristic of most $P$. stutzeri strains, but exceptions have been described (strain JM300 is amylasenegative, strain ZoBell is described as non-motile). New 
Table 2. DNA-DNA relatedness values (\%)

The strains used for comparisons were the same as in Table 1.

\begin{tabular}{|lcccc|}
\hline Dissimilarity measures & Mean & Median & Max. & Min. \\
\hline Among new genomovars 11 to 18 & 52 & 56 & 82 & 28 \\
Comparison of reference strains of new genomovars 11 to & 38 & 45 & 68 & 9 \\
18 to reference strains of established genomovars 1 to 10 & & & & \\
Comparison of reference strains of new genomovars 11 to & 31 & $22 \cdot 5$ & 60 & 10 \\
18 to Pseudomonas balearica DSM 6083 ${ }^{\mathrm{T}}$ (former gv. 6) & & & & \\
\hline
\end{tabular}

genomic species, as indicated here by DNA-DNA hybridization for the eight strains, should not be classified as novel species unless differentiating phenotypes are found (Rosselló-Mora \& Amann, 2001; Stackebrandt et al., 2002; Ursing et al., 1995), which is not the case here. Thus, we propose eight new genomovars, 11 to 18 , of $P$. stutzeri, with strains 28a50, 28a39, 28a22, 28a3, 4C29, 24a13, 24a75 and strain MT-1, respectively, as the reference strains for each genomovar. The strains have been deposited as CCUG 50538-50545 (=DSM 17082-17089).

It is remarkable that strain 28a18 (Sikorski et al., 2002a) was found to be highly similar to the genomovar 14 representative 28a3, with a DNA-DNA relatedness value of $91 \%$ (Supplementary Table S1 in IJSEM Online), yet this strain had a position in the $16 \mathrm{~S}$ rRNA tree different from that of 28a3 (Supplementary Fig. S1 available in IJSEM Online). The two strains were isolated from the same soil sample and are nearly identical in their ITS1 sequences (Supplementary Fig. S2 available in IJSEM Online), their RAPD patterns (Sikorski et al., 2002a) and their partial $r p o B$ sequences [as determined by restriction enzyme profiling of $1.5 \mathrm{~kb}$ PCR products (nucleotides 532 to 2034 of the Escherichia coli rpoB sequence); J. Sikorski and W. Wackernagel, unpublished]. The divergence of their $16 \mathrm{~S}$ rRNA gene sequences results from five nucleotide changes within a stretch of 15 nucleotides (E. coli positions 74 to 92; $E$. coli has an insert of four nucleotides compared with all $P$. stutzeri strains), which makes the $16 \mathrm{~S}$ rRNA gene sequence of strain $28 \mathrm{a} 3$ in this region identical to that of genomovars 2 and 3 strains. This rare specific local sequence identity between a single member of one genomovar and the members of two far-distant genomovars may be explained by a horizontal gene transfer event involving part of the 16S rRNA gene. Strain 28a3, as the putative recipient, was shown to be highly transformable, which is generally not the case for strains of the RAPD group of which $28 \mathrm{a} 3$ is the representative (Sikorski et al., 2002b).

\section{Acknowledgements}

J.S. is grateful for a research stay at the Departament de Biologia of the Universitat de les Illes Balears (Spain). This work was supported by grants from the Federal Ministry of Research and Technology (Germany), the Fonds der Chemischen Industrie (Germany) and the CICYT (Spain) project BOS2001-0303. The help of Maria Valens and Christina Ramon in DNA-DNA hybridization experiments is highly acknowledged. Also, the help of Ramon Rosselló-Mora in DNA-DNA hybridization, phylogenetic reconstructions and many helpful discussions is greatly acknowledged.

\section{References}

Bennasar, A., Rosselló-Mora, R., Lalucat, J. \& Moore, E. R. (1996). $16 \mathrm{~S}$ rRNA gene sequence analysis relative to genomovars of Pseudomonas stutzeri and proposal of Pseudomonas balearica sp. nov. Int J Syst Bacteriol 46, 200-205.

Berndt, C., Meier, P. \& Wackernagel, W. (2003). DNA restriction is a barrier to natural transformation in Pseudomonas stutzeri JM300. Microbiology 149, 895-901.

Cladera, A., Bennasar, A., Barceló, M., Lalucat, J. \& García-Valdés, E. (2004). Comparative genetic diversity of Pseudomonas stutzeri genomovars, clonal structure, and phylogeny of the species. J Bacteriol 186, 5239-5248.

Garcia-Valdés, E., Castillo, M. M., Bennasar, A., Guasp, C., Cladera, A. M., Bosch, R., Engesser, K. H. \& Lalucat, J. (2003). Polyphasic characterization of Pseudomonas stutzeri CLN100 which simultaneously degrades chloro- and methylaromatics: a new genomovar within the species. Syst Appl Microbiol 26, 390-403.

Guasp, C., Moore, E. R., Lalucat, J. \& Bennasar, A. (2000). Utility of internally transcribed 16S-23S rDNA spacer regions for the definition of Pseudomonas stutzeri genomovars and other Pseudomonas species. Int J Syst Evol Microbiol 50, 1629-1639.

Kumar, S., Tamura, K., Jakobsen, I. B. \& Nei, M. (2001). MEGA2: molecular evolutionary genetics analysis software. Bioinformatics $\mathbf{1 7}$, 1244-1245.

Ludwig, W., Strunk, O., Westram, R. \& 29 other authors (2004). ARB: a software environment for sequence data. Nucleic Acids Res 32, 1363-1371.

Marmur, J. (1961). A procedure for the isolation of deoxyribonucleic acid from microorganisms. J Mol Biol 3, 208-218.

Meier, P. \& Wackernagel, W. (2003). Mechanisms of homologyfacilitated illegitimate recombination for foreign DNA acquisition in transformable Pseudomonas stutzeri. Mol Microbiol 48, 1107-1118.

Musarrat, J. \& Hashsham, S. A. (2003). Customized cDNA microarray for expression profiling of environmentally important genes of Pseudomonas stutzeri strain KC. Teratog Carcinog Mutagen (Suppl. 1), 283-294.

Obradors, N. \& Aguilar, J. (1991). Efficient biodegradation of highmolecular-weight polyethylene glycols by pure cultures of Pseudomonas stutzeri. Appl Environ Microbiol 57, 2383-2388.

Rius, N., Fusté, M. C., Guasp, C., Lalucat, J. \& Loren, J. G. (2001). Clonal population structure of Pseudomonas stutzeri, a species with exceptional genetic diversity. J Bacteriol 183, 736-744. 
Rosselló, R. A., García-Valdés, E., Lalucat, J. \& Ursing, J. (1991). Genotypic and phenotypic diversity of Pseudomonas stutzeri. Syst Appl Microbiol 14, 150-157.

Rosselló-Mora, R. \& Amann, R. (2001). The species concept for prokaryotes. FEMS Microbiol Rev 25, 39-67.

Rosselló-Mora, R. A., Lalucat, J. \& Garcia-Valdés, E. (1994). Comparative biochemical and genetic analysis of naphthalene degradation among Pseudomonas stutzeri strains. Appl Environ Microbiol 60, 966-972.

Rosselló-Mora, R. A., Lalucat, J. \& Moore, E. R. B. (1996). Strain JM300 represents a new genomovar within Pseudomonas stutzeri. Syst Appl Microbiol 19, 596-599.

Sepúlveda-Torres, L. C., Zhou, J., Guasp, C., Lalucat, J., Knaebel, D., Plank, J. L. \& Criddle, C. S. (2001). Pseudomonas sp. strain KC represents a new genomovar within Pseudomonas stutzeri. Int J Syst Evol Microbiol 51, 2013-2019.

Sikorski, J., Graupner, S., Lorenz, M. G. \& Wackernagel, W. (1998). Natural genetic transformation of Pseudomonas stutzeri in a nonsterile soil. Microbiology 144, 569-576.

Sikorski, J., Moehle, M. \& Wackernagel, W. (2002a). Identification of complex composition, strong strain diversity and directional selection in local Pseudomonas stutzeri populations from marine sediment and soils. Environ Microbiol 4, 465-476.
Sikorski, J., Teschner, N. \& Wackernagel, W. (2002b). Highly different levels of natural transformation are associated with genomic subgroups within a local population of Pseudomonas stutzeri from soil. Appl Environ Microbiol 68, 865-873.

Smibert, R. \& Krieg, N. R. (1994). Phenotypic characterization. In Methods for General and Molecular Bacteriology, pp. 607-654. Edited by P. Gerhardt, R. G. E. Murray, W. A. Wood \& N. R. Krieg. Washington, DC: American Society for Microbiology.

Stackebrandt, E., Frederiksen, W., Garrity, G. M. \& 10 other authors (2002). Report of the ad hoc committee for the re-evaluation of the species definition in bacteriology. Int J Syst Evol Microbiol 52, 1043-1047.

Tamegai, H., Li, L., Masui, N. \& Kato, C. (1997). A denitrifying bacterium from the deep sea at 11,000-m depth. Extremophiles 1, 207-211.

Ursing, J. B., Rosselló-Mora, R. A., Garcia-Valdés, E. \& Lalucat, J. (1995). Taxonomic note: a pragmatic approach to the nomenclature of phenotypically similar genomic groups. Int J Syst Bacteriol 45, 604 .

Ziemke, F., Hofle, M. G., Lalucat, J. \& Rosselló-Mora, R. (1998). Reclassification of Shewanella putrefaciens Owen's genomic group II as Shewanella baltica sp. nov. Int J Syst Bacteriol 48, 179-186.

Zumft, W. G. (1997). Cell biology and molecular basis of denitrification. Microbiol Rev 61, 533-616. 